\title{
The making of a petrol station and the "on-the-move consumer": Classification devices and the shaping of markets
}

\author{
Frank Azimont ${ }^{\mathrm{a}, *}$, Luis Araujo ${ }^{\mathrm{b}}$ \\ a E.M. Lyon, 23 avenue de Collongues, 69132 ECULLY Cedex, France \\ b Department of Marketing, Lancaster University Management School, LANCASTER LA1 4 YX, UK
}

\section{A R T I C L E I N F O}

Article history:

Received 30 May 2009

Received in revised form 7 April 2010

Accepted 19 May 2010

Available online 8 July 2010

\section{Keywords:}

Classification

Calculation

Category management

Market segmentation

\begin{abstract}
A B S T R A C T
This paper addresses the issue of classification devices and their role in shaping markets. We depart from the notion that markets are shaped by multiple calculative agencies and examine how particular forms of calculation are made viable. Classification devices are the infrastructure that makes calculation possible and sustains particular economic orders. We illustrate these notions with an empirical, longitudinal study of a fuel retail company and its initiative to re-classify its network of petrol stations across Europe. Our study focuses on the extensive and protracted negotiations over what constituted relevant categories and the multiple perspectives involved in defining petrol station types. We illustrate how a store typology plays an important role in making assemblages of ideas (e.g. consumer-on-the-go), objects (e.g. store planograms), and managerial roles (e.g. category managers) coalesce around particular constellations of practices which impact upon the outline of markets.
\end{abstract}

(c) 2010 Elsevier Inc. All rights reserved.

\section{Introduction}

This paper focuses on the role of classification systems in the construction of economic orders, namely firms and markets. It follows in the wake of recent work that connects the "markets-as-networks" approach to market studies and is inspired by the sociology of science and technology (Mattsson, 2003). In this tradition, markets are performed and shaped by multiple calculative agencies (Callon \& Muniesa, 2005; Kjellberg \& Helgesson, 2006). Market practices bring together a variety of market actors acting in accordance with different market representations and engaging in divergent practices, each trying to shape the market in different ways (Araujo, 2007; Azimont \& Araujo, 2007). The role of marketing is performative - i.e. engaged in the production of the very phenomena it purportedly describes. The focus on calculative devices has provided us with rich insights on the nature of markets. However, the interest in calculation hasn't been matched by an interest in how particular modes of calculation are deployed in efforts to govern economic life (Miller, 2008). To put it differently, how do modes of calculation embody particular ideas about how economic orders should be constructed? One way of linking calculation to ideas is to focus on the role of classification systems (Bowker \& Star, 2000). Classification systems are powerful yet often invisible technologies generating everyday categories that quickly disappear from view, inscribed in infrastructures and takenfor-granted routines. To date, few empirical studies have examined

\footnotetext{
* Corresponding author.

E-mail addresses: azimont@em-lyon.com (F. Azimont), l.araujo@lancaster.ac.uk (L. Araujo).
}

this interaction between calculation and classification systems. One notable exception is Sjögren and Helgesson (2007), who highlight the role played by classification devices in linking medical and pharmaceutical classifications to health care provision and economic value.

Classification systems operate at all levels. Within firms, managerial roles are specified, graded and rewarded according to established taxonomies. At the level of markets and industries, think of types of retail formats, standard industrial classifications or the division of populations into geo-demographic segments. At the national level, consider national accounts or the balance of payments to keep track of flows of goods across national boundaries. At the supranational level, the formulation of international product standards, technical norms and trade rules through international institutions constitute further examples of the importance of classification in economic life (Stark, 2009).

Our aim in this paper is to examine the role of classification systems linking firms to markets. Our empirical study focuses on how efforts to create market segments by a petrol retailing company involved complex processes of classification at different levels. Creating a typology of customers involved a reclassification of retail stores with consequential impact on the grading of jobs within the company and sparked off a discussion on the retailing strategy the company should follow. Classification work required inputs from customers, through the organization of focus group sessions, and provoked serious internal debates within the company. The outcome of this process was the creation of a classification that aligned different versions of customers with store types and the qualification of managerial jobs required to operate this assemblage.

The paper is structured as follows: in the next section we review the literature on classification devices in the field of marketing and the 
sociology of commensuration. In the third section, we briefly describe our empirical setting and the methodology used in our study before presenting our empirical material in the fourth section. In the fifth section, we draw together the main threads of our analysis and conclude with reflections on the issues that emerge from this study.

\section{Making market shaping intelligible}

We start this section by revisiting the relationship between the economy and the disciplines that address economic practices, including economics and management studies. The key argument of the performativity program is that economics, broadly construed, does not just describe how the economy functions (Callon, 1998). Ideas, models, techniques, methods and professional practices related to the economy actively constitute and render visible the subject domain of economics and management (Porter, 2008). To manage is to be able to establish a correspondence between the world "out there" and the techniques of representation (e.g. lists, hierarchies, and statistics) that abbreviate and condense the essential features of that world (Cooper, 1992). Czarniawska and Mouritsen (2009) argue that management is essentially a process of turning the complexity embodied in things and people into simplified quasi-objects that can be treated and acted upon as discrete and separate entities.

Calculation is central to the understanding of how economic entities are made visible and governable. Calculation, in Callon (1999) terms, designates the processes which make possible the assignment of numbers (such as prices or rankings) to entities, an assignment which endows these entities with relative stability and makes possible their circulation. As pointed out by Espeland and Stevens (1998), commensuration, or the transforming of different qualities into a common metric, is one important part of this process. Before calculation is possible, things must be placed in some kind of order to allow work to be done on them (Bowker \& Star, 2000). Classifications such as standards (e.g. quality certificates, accounting rules) places boundaries around objects and activities and render a degree of order to an otherwise chaotic world. Managerial jobs, for example, are usually described and ranked in some kind of hierarchy and pay scales grade the roles and contributions of individuals to an organization.

Callon and Muniesa (2005: 1231) propose a broader view of calculation that is not confined to the performance of numerical operations or the use of ratio scales. Instead, they suggest that calculation involves three distinct steps. First, entities must be detached from their contexts, classified and ordered within a single space (e.g. a trading screen, a spreadsheet). Secondly, once ordered in that space, these entities can be compared, manipulated and transformed according to particular rules (e.g. aggregating performance indicators at the product level to calculate performance at the store level). Thirdly, results such as a ranking of suppliers must be produced that both summarize and represent the entities in that calculative space.

Similarly, Cochoy's $(2002,2008)$ notion of qualculation stresses that calculations draw on qualitative and quantitative components, metrics as well as judgments. Defining the qualities of things is integral to their calculability (Callon et al., 2002). All measurement systems are made possible by calibration, understood as the creation and determination of quanta (Power, 2004). The creation of quanta is a special case of metrology, which requires technical instruments to make phenomena standardized and measurable. This requires the establishment of frames, the decontextualization of objects, and the grouping and comparing of objects in the same frame. Once quanta are established, they can be subject to further calculative operations.

The performative roles of both classification devices and calculation have long since been studied by accountants. Carruthers and Espeland (1991), for example, evoke the power of accounting tools and inscriptions (e.g. figures, charts, tables) in performing calculations. For Miller (2001), accounting represents an essential set of devices for acting upon individuals in an attempt to ensure that they behave in accordance with particular economic objectives. Accounting practices contribute to both the make-up and the transformation of the entities they seek to represent.

Desrosières (2003) makes a similar case regarding the role of statistics in government. Classification devices structure the environment by imposing categories and framing issues. The definition of an index, for example, is a political decision. The economists and statisticians who came up with the notion of gross domestic product (GDP) as a measure of economic output were well aware that questionable choices were built into the index. Desrosières shows, for example, how domestic work was excluded from the GDP measure despite intense controversies on the subject. In short, agents are only able to calculate once equipped with appropriate classification instruments that determine what can be counted and what cannot.

The accounting literature has provided us with useful insights on how classification systems and modes of calculation transform the identities of individuals as producers and constitute them as calculable subjects (see e.g. Miller \& O'Leary, 1994). In doing so, it focused primarily on hierarchies and only recently has it shown an interest in inter-organizational phenomena (see e.g. Håkansson \& Lind, 2004; Mouritsen \& Thrane, 2006). The marketing literature has long since employed a host of classification devices in a bid to represent and intervene in markets. The notions of market segmentation and product differentiation pioneered by Smith (1956) provide a strong reminder of the importance of classification in marketing. Markets can be disaggregated and a classification system built to characterize smaller and homogeneous segments of demand leading to differentiated offerings targeted at those segments. The heterogeneity of markets and the homogeneity of demand schedules within segments is a managerial construction, underpinned by a more or less explicit classification system.

Whereas there is an abundance of examples of segmentation taxonomies for consumer and industrial markets in the academic literature, examples of how segmentation strategies are carried out in practice are scarce. We know relatively little about how classification systems are deployed in market segmentation, how they interact with existing classification systems and how that interaction shapes the way firms relate to markets. The role of classification systems, we suggest, is critical in understanding the relationship between firms and markets.

\section{Method}

Our empirical study focuses on the petrol retailing arm of a large European oil company, here labeled BEST to preserve anonymity. In the course of the calendar year 2003, BEST initiated a move from a product to a category management structure. This move was accompanied by a change in responsibilities, work processes, as well as performance indicators used by category managers. The empirical material is based on the processes that helped organize the work of category managers and structure the representations of the company's petrol station network and customers. We used Latour's (2005) injunction to follow actors and artifacts to structure our data collection and analysis. The first author sat through meetings where the marketers involved in the various countries where the company has a presence (here labeled Rapland, Discoland, Rockland and Groveland to disguise their identity), discussed the categorization of retail stores in their respective networks. We were primarily concerned with understanding the categorization logic used by managers to come up with store types that had thus far been referred to simply as "petrol stations".

The first author acted as an observer, following a period of involvement with the organization as a researcher, trainer and consultant. The role adopted was that of observer-as participant (Ackroyd \& Hughes, 1992: 135). In management research this strategy has been mainly employed in longitudinal studies of organizations 
(Kunda, 1992; Watson, 1994) or projects (Gersick, 1989). The major argument for the use of participant observation method is that it facilitates an insider's perspective in naturally occurring phenomena in a particular organizational or social setting. One obvious difficulty in this research strategy is the balance between the roles of researcher and participant.

The first author had developed contacts and relationships with key individuals in the focal company as part of a broader longitudinal study centered on category management over a 4 year period from 2002 to 2006. At first, his involvement with the company was based on information and training sessions related to the benefits of implementing category management in large grocery retail companies. After this initial phase when the researcher gained access to some of the key senior managers in the company, he was allowed to carry out a research project and observe the meetings related to the implementation of category management within BEST. This project relied on a continuous involvement with the company. It was based on a variety of data collection mechanisms, including interviews, field observations and action research initiatives such as training seminars. The involvement with the company facilitated access to a range of materials used in this study, namely company documents, Excel spreadsheets and database requests used by the managers to analyze the performance of products and suppliers.

\section{Creating a store typology as a classification device}

The role and features of petrol stations have changed enormously over the last three decades. In the early days, forecourts were primarily seen as the site where vehicles were refueled and maintained. The development of forecourts as separate entities from automobile garages made fuel delivery central to the notion of a petrol station. The petrol station was primarily regarded as a fuel delivery area with a kiosk attached. Progressively, products such as confectionary and drinks were offered to drivers when paying for fuel. The offer of non-fuel items expanded from the payment zone to the full area of the outlet. In the late 1990s, when store sales generated a higher margin than fuel sales, the still-called "petrol stations" became points of sale addressing the needs of people on-the-move. Offers targeting drivers' comfort became a major profit lever for fuel retailers. Car maintenance items such as light bulbs or windscreen wipers became a minor sideline and only remained in the assortment to comply with regulatory reasons.

Our case documents the way BEST moved towards this differentiated landscape of petrol stations after it discovered that many consumers stop at petrol station without buying fuel. Based on an analysis of check-out sales receipts, the European marketing managers observed that many receipts did not contain a fuel purchase line, only food or beverage items. This observation led the marketing team to imagine that a fresh food offer, displayed in the manner of a small grocery store might be attractive to consumers namely in the proximity of large cities. Our study focuses on how one shop concept (labeled CONCEPT) based on a fresh food offering was deployed throughout BEST's European network after a prototype was tested during March 2003 in Discoland.

After the successful launch of CONCEPT in Discoland and the opening of two more stores in other European sites, a launch assessment meeting was organized in June 2003 by the retail directors. Mike, who had led the deployment of category management at the European level, had been closely involved with his newly created team of category managers to generate CONCEPT. At this meeting, Mike was entrusted with a mission he regarded as particularly challenging: to roll out CONCEPT throughout the company's European network. Although the first three sites to be refurbished in every country had already been determined, further sites had yet to be identified. For this purpose, the European head of retail asked Mike to generate a detailed description of the network - in short, a database of all European sites with a comprehensive report on their level of equipment.

It turned out that the networks in different countries were very disparate. There were virtually no two stores with the same area, or the same retail equipment in terms of say, shelves or chillers. That's why, Mike believed, drawing such a big picture would be useful for his own projects starting with the roll out of CONCEPT and the deployment of category management in each country. He believed that this new assignment would be an opportunity to prove the expertise of category managers in terms of managing the shop business. As category managers positions were in the process of being introduced within the organization, CONCEPT was under scrutiny to assess both its intrinsic business attractiveness as well as the ability of this new kind of retail managers to run such projects. Mike framed the rationale for welcoming the assignment in the following terms:

"We should find a way to classify these stores with a system that moves away from an ownership principle. COCO (company owned, company operated) and CODO (company owned, distributor operated) are certainly appropriate categories when the objective is to minimize fuel distribution costs. But if we want to enhance our leadership position in Europe, we have to be consumer-oriented and understand what consumers expect from a station when they stop. From an efficiency perspective, once clusters have been identified, we will simplify the work of our category managers who will no longer have to define an assortment or a planogram for each station but rather for each type". (Mike, Marketing director, CONCEPT launch assessment meeting, June 2003)

Category managers had discussed the relevance of CONCEPT in 2002 and the debate was steered, at Mike's request, on the practical issues needed for setting up one test store: "here is the store that we want to refit", "please define the range of products that you want for this sales surface", "the collection should fit on 3 elements", "execute your planogram", "this need to be OKed by March", etc. These were the type of instructions given by Mike to the category managers who formed part of the task force.

All these recommendations were easy to implement because they applied to one site only. But as soon as the roll out to a larger store base was considered, Mike anticipated all sorts of difficulties. The variety of sites would cause problems for the category managers because they would have to replicate the work across as many stores for each country unless a typology of stores could be established. If a typology could be established, many processes would be made easier for anybody who would need to roll out an initiative across a network:

"If we want to be able to set priorities easily, we need a precise picture of the network. We will then be able to decide which station should be positioned with CONCEPT, in the first instance. And by the way, the same applies to the selection of a site for a restaurant concept, to car wash investments, or to any other priority which may arise. In relation to the job of the category managers, we need to understand what area to dedicate to one product family. If we develop a typology based on consumer insights, this will give us a rationale to decide and explain why any product family is given this much amount of space." (Mike, Marketing Director, CONCEPT launch assessment meeting, June 2003)

At the start of his mission, Mike kept in mind the key targets set by the company: to reach a market share of $22 \%$ in Europe and generate an operating margin of $13 \%$ with two main assets, a large network of stores and a reputable brand in most countries. Mike could have restricted his task to the creation of a database listing the physical attributes of the stations, such as the sales area, the fuel volume, the number of parking places and the turnover made by key product families, which were the criteria normally used to depict a network at 
BEST. But he wanted to push descriptions further by integrating a demand side perspective, as he explained to the first author in a private conversation:

"If we want to do a serious job, we have to put customers at the core of our processes; we certainly need to understand how customers perceive our stores. Our recommendations will be made stronger by the adoption of a real marketing perspective." (Mike, Marketing Director, CONCEPT launch assessment meeting, June 2003)

\subsection{Generating store types}

After selecting a market research agency to help him create a typology of retail stores, Mike instigated the creation of several focus group sessions with consumers throughout Europe - see Lezaun (2007) on the production of opinions in focus group sessions. To determine the sample, a simple classification of demand was supplied to the agency. In broad terms, customers fitted into two main categories: those for whom transportation was a daily routine but not a job (e.g. daily trips to school or to the office) and those who needed to be on the road to perform their jobs (e.g. truck drivers, sales representatives). The time spent by passengers in a car everyday was also a factor to be taken into account. This reflected the notion that many people spent several hours a day in their car even if they could not be classed as professionals. "For most of us, the vehicle has become a space of everyday life so that it might well have an impact on the way customers experience our stations", Mike wrote in his brief to the agency.

The agency recommended the organization of focus groups with private drivers and passengers as well as running separate sessions with truck drivers or sales reps on station premises. During the focus group sessions, that took place during September 2003, participants were invited to express why they usually stopped at a petrol station. Based on these comments, a list of motivations was written on a flipchart by the agency's moderator. For example, some consumers stopped at one station because they need to use the toilet facilities. When stopping at one particular place, they expected the facilities to be clean. Other consumers stopped to get a hot coffee and rest for a few minutes. For these consumers, a large and properly lit area, with access to a coffee machine and a range of hot beverages were the key features they expected from a petrol station. While consumers talked, the assistant of the focus group moderator searched for visuals to depict these motivations on the Internet. The visualization of products or the functions that had to be delivered by a station were then injected into the discussion. Concept cards were finally created with these visuals and descriptors printed on them. Consumers were asked to name these concept cards and to group them on larger boards. A denomination had to be given to each type created. Using this method, seven types of stations were created: motorways, main roads, truck meeting points, workplaces, commuter stops, convenience stores and "grand pa" stations.

In October 2003 a separate meeting was organized in Rockland to debrief the focus groups' results with the category managers who had contributed to the development of CONCEPT. The objective was to confront the types created through the focus group sessions with the existing attributes used to describe the stations within the company. The complementarities of the two approaches would make the typology more robust, Mike hoped. In the following subsections we describe the various types generated by the focus group together with the comments of category managers as they were confronted with the data generated by the focus groups.

\subsection{Motorway stations}

Motorways stations, consumers suggested, have to provide a good environment for customers who want to take a break. The facilities (e.g. toilets, rest areas), services (e.g. ATMs, telephones, TVs, Wi-Fi area) and food on-the-go (e.g. sandwiches, hot and cold beverages) are essential features. Consumers also suggested that an offer of regional products could be interesting. What about non-food products, the moderator asked? They are interesting because the shopping trip through the store is a kind of distraction:

"While drinking a coffee or a hot soup, I like to circulate through the shop and look at what is on display". (A consumer, focus group in Rapland, September 2003)

When this first type was presented to the category managers they could easily translate these descriptions into technical features of a station. They pictured a store with a surface area from 120 up to $250 \mathrm{~m}^{2}$, an annual turnover of $€ 2$ million and minimum fuel sales of $1200 \mathrm{~m}^{3}$. The traditional motorway station had a minimum of 30 customer parking spaces, was opened 7 days a week, $24 \mathrm{~h}$ per day and stocked 2000 to 2500 items.

In Rapland, this type of store could include up to 160 sites: "In the other countries, we would need to calculate the numbers that can fit into this type but this should be an easy task" (Uwe, category manager in Rapland, Rockland meeting, October 2003).

\subsection{Main road stations}

A similar type to motorway stations was described by consumers in what they called "main road stations". Located on the major road network joining large cities, these stations played the same role as their siblings on the motorways: catering for driving breaks.

"... on average I stop for 15 minutes, refill, go to the toilet and get a coffee as well as a breath of fresh air." (consumer, focus group, Rapland, September 2003)

In Rapland, there were probably another 160 stores that would fit this description, which meant that this category could be as large as the motorway stations. However, the supply logistics would have to be different from motorway stations. The suggestion was that: "Since this cluster is large enough, let's make it a different category" (Uwe, Category manager, Rockland typology meeting, Oct 2003).

\subsection{Truck meeting points}

When discussing the reasons for avoiding stations, a number of focus group participants mentioned that they didn't like stations where there were too many truckers. These vehicles occupy too many parking places and are too dangerous for the kids, they claimed. In the store, truck drivers gather in numbers to eat and drink and can be noisy, which seemed to bother some people. Using these insights as a starting point, the moderator pushed the idea of creating a separate truck stop station. The proposed idea would need to be worked through with truck drivers themselves. The interviews carried out at the point of purchase showed that professional truck drivers stop at a station primarily because shower facilities are convenient and clean, but also because they know that they can park easily, meet other truckers around an informal sit-down meal, and watch TV for a while, particularly on days featuring important soccer matches.

Category managers added to this description by including other items they believed were useful for a comfortable journey: ATMs, currency changing facilities, telephones, but also maps, accessories, and apparel. The technical and financial profile of this category would be very similar to the motorway type. The key differentiating factor appeared to be shower facilities and a restaurant. In some countries, because of licensing issues petrol stations were not allowed to serve sit-down meals although a bar option could be considered.

"The custom base of the truck stops is simply different from the rest of the motorway stations and seems to fit poorly with the 
profile of other travelers. Why not create a specific type which could well be appropriate for say, 30 to 50 units in each country?"

(Geoff, category manager, Rockland typology meeting, Oct. 2003)

In reality, this type was already in existence in three countries although not in Rapland. The locations which could serve as truck meeting points would need to be identified. The factors to consider would include the location of industrial regions, the identification of the main truck transportation routes as well as the ideal distance between stations. But, all in all, this type made sense to the category managers.

\subsection{The commuters' stop}

The main circulation routes in and out of major cities, focus group participants wondered, should have their own category. In the morning, fresh coffee and pastries together with newspapers should be on sale. The primary reason why people stop there at this specific moment of the day is, for the early birds, to have breakfast before rushing to the office. In practical terms, this meant that a coffee corner and fast lanes should be put in place. For the evening commuters, a similar idea would apply with an offer of wine, flowers, gifts and even ready-to-eat meals.

The category managers could easily see how this scenario would work out in practice. However:

"The question is to know if we should have two types, a morning station and an evening station. Can we get the two concepts in the same store? Inward stations will have a nice breakfast business but exit stations will need to focus on other selling points." (Susie, category manager, Rockland typology meeting, Oct. 2003)

In terms of size, these stores would have a $40-75 \mathrm{~m}^{2}$ sales area, deliver a minimum fuel sale of $600 \mathrm{~m}^{3}$, be opened 7 days a week, $16 \mathrm{~h}$ per day and have a minimum of three customer parking spaces:

“... we could imagine positioning these stores to help time-pressured people to start or end the day better with a specific focus on breakfast or take-away food and drink solutions. In Rapland, we could probably set up 35 stores of each subtype. Now, are we not creating too many clusters which mean a multiplication of product ranges, planograms and certainly, difficulties in implementing our marketing programs through the district managers?" (Anna, category manager, Rockland typology meeting, Oct. 2003)

Though the commuters' stop option made sense to the managers attending the meeting, Anna could imagine that the proliferations of types would have significant consequences for management. The consumer perspective was one important aspect but the ability to manage this diversity would need to be included in the discussion.

\subsection{Workplaces}

The first four types, the motorway, the truck stops, the main roads and the commuters' stations, were obvious to the category managers because they fitted with recognizable types already in existence in the company's European network. However, the distinction between entry and exit routes in commuter stop stations was not articulated spontaneously by focus group participants. The workplace idea came from a focus group participant who commented on the absence of a corporate restaurant in her workplace. She explained why she escaped from the office during the lunch break. She would, for example, go to the bank or do some shopping during the lunchtime break. She liked to stop at the local station where the owner's wife prepared something fresh every day. Fresh, not machine coffee, was also available, she insisted.
This idea was puzzling to category managers at first. The number one role of a workplace station, as described by this lady, would be a restaurant. She did not mention the need to refill at any time. What was of interest to her was the convenient location of the shop on the way from or to the office, with a few parking spaces catering for a short stop. With a limited monthly fuel volume, the type of store she was describing was rated as a problematic type to implement. In fact, the company had sold off a number of these stores following a recent merger with another fuel retail company. Managers at Rapland for example, were considering getting rid of this type of store altogether.

Category managers had no clear idea about the relevance of this type because they were hardly involved in the restaurant business and felt the company was not particularly good at setting up restaurants. By contrast, a company like Auto Grill, the European leader, was seen as a real expert in this area. Still, a quick calculation was made based on the number of stations with a small restaurant that delivered daily meals. The calculation showed that workplace stations could represent a very significant share of a network's profit.

"We can currently identify 40 stores with this potential which, with the profile we know from the restaurant stations located on the main roads, could easily deliver $30 \%$ of our domestic profits." (André, category manager, Rockland typology meeting, Oct. 2003)

"This is right but we are not restaurant specialists. Can you seriously imagine developing this know-how without a partnership?" (Joe, category manager, Rockland typology meeting, Oct. 2003)

The option of a partnership was suddenly taken seriously:

"We are specialists of consumption on-the-go. To get to our stations, drivers take their car, and we know their needs better than anyone else in the country. Why not think of our stores as a combination of modules? I wouldn't see a major issue in having a McDonald's restaurant in our stores. After all, young people meet up at our stations, buy Red Bull and cigarettes, before they move to a night club. In many cities, they show up to buy beer and sit in a park next to the station for the whole night." (Jennifer, category manager, Rockland typology meeting, Oct. 2003)

A simple consumer story had sparked the imagination and category managers thought that this particular type of petrol station could be profiled in a much sharper way in future. The next type described by consumers generated a similar level of excitement.

\subsection{Convenience stores}

In recent years, petrol stations in large cities had been sold by the major fuel retail operators because they were too difficult to operate. This trend continued until someone noticed that these stores were systematically acquired by small business entrepreneurs in the bakery and food sectors. Thereafter, some of the petrol retailers had decided to make a convenient store out of these stations. After many trials, BEST concluded that with a minimum of 5 customer parking spaces, these stations could stock a range of up to 2500 product lines in a $150 \mathrm{~m}^{2}$ space and generate an average turnover of $€ 61 \mathrm{k}$ per annum with $83 \%$ coming from food sales. Consumers were using these outlets as proximity stores for top-up purchases on their way home.

For category managers and Mike, this cluster was precisely the one where CONCEPT would need to be rolled out. But in Rapland, a recent market research study carried out within a sample of stations showed that $40 \%$ of the customer base came to the store on foot and bought an average of 7 items per basket, out of which 2 were fresh food items. In other words:

"We play the role of a local grocery store. The size we are talking about is smaller than that of Aldi [the German low cost retailer] 
but our range is double of Aldi's. Our prices are far more expensive but we deliver fruit and vegetables and have an offer of dairy products. I doubt we can be a serious player on the discount side but if we choose our location carefully, we could have a good business out of these stores within large cities, for example. Our opening hours would give us a real advantage." (Barbara, category manager, Rockland typology meeting, Oct. 2003)

Discussing how far BEST could run with the convenience store idea, category managers mentioned the organization of Rockland who had set up a partnership with a multi-format retailing company, TESCO [the British-based grocery retailer]. This partner had expertise in delivering fresh food to local proximity stores at a low cost because of the dense network of its TESCO Express shops. The deal was working well, as agreed by all, because the local category managers were following the procedures given to them by their partner, a retail expert. But the comments mixed admiration for the partner's expertise with worries:

"It is as if our category managers would be the employees of the partner. They have the same computer interface, the same procedures, the same referential of products and suppliers, etc. We even wonder if this deal is not set in anticipation of a future sale of the business to TESCO Express, a kind of merger before the acquisition!" (Geoff, category manager, Rockland typology meeting, Oct. 2003)

On one hand, it was clear that the "convenient store" cluster was the ideal one to roll out CONCEPT but as the discussion stressed, a partner might be needed to compete with hard discounters. A price premium of $15 \%$ was the maximum consumers would be ready to pay, commented some category managers.

"And to reach this price, not only do we need to have efficient logistics, which most of our wholesalers are unable to provide in the fresh food category, but we need to have a volume which will enable us to get good prices. In that sense, we cannot afford to have too many clusters because this process creates too much diversity within a distribution channel which in itself is very small compared to the supermarket channel." (Ben, category manager, Rockland, typology meeting, Oct. 2003).

\section{8. "Grand Pa's" petrol station}

Finally, focus group participants reminded the company that they should not forget the "Grand Pa" petrol stations, the traditional fuel stations attached to a garage or a local car dealership. These stations, consumers commented:

“....are essential parts of local life, particularly in rural area. This is the place where you can order fuel for the home central heater, this is where you like to go to service your car, but also get your lawn mower repaired, and this is where you fill up as well. Of course, prices are not the lowest but you want to contribute to the community and maintain activity in the village." (A consumer, focus group, Discoland, Sept. 2003)

\section{A category manager had a quick reaction to this comment:}

"And these are the stations where we lose as much money as we want! We don't want to spend time on this cluster because we will never roll out CONCEPT here. We should put these stations on the write-off list (Susie, category manager, Rockland typology meeting, Oct. 2003).

These stations, the category managers observed, should not be operated by BEST anymore even if they fulfilled a recognizable customer need.
Thus far, through a process of confronting insights from the focus group sessions with the category managers' knowledge of their networks, Mike had settled on a qualitative description of seven distinct categories of stations. After the qualitative research phase, the market research agency ran a cluster analysis in November 2003. The method consisted of grouping, step by step, the types which had been defined qualitatively by the focus groups. Consumers were asked to get together the two groups they thought were the closest. The initial 7 groups were reduced to 6 by pairing together the two closest groups. In the following run, they were asked to do the same until the last two groups were paired together. This methodology resulted in a cluster structure that formed the basis for a classification of the network. Finally, consumers were asked to name each of the categories generated by the cluster analysis. Long distance trips, Rest areas, Daily trips, Essentials, Neighborhood stations were the name given to the successive groupings of clusters. Fig. 1 shows the resulting dendogram generated by consumers and validated by the category managers from the countries where BEST operates:

\subsection{Cutting the segmentation tree}

At this stage, in December 2003, Mike and his task force thought they had achieved something and done it in a rigorous fashion. The classification system would gain legitimacy, they hoped, because it had been driven by consumer insights. An important issue remained: at what level should the typology tree be cut? Different types of logic could be considered. From an operational perspective, the more junior the category managers were the less complexity they would be able to handle, which pointed towards a high level of standardization in the network. Category managers would be graded at level 7, a junior manager according to BEST's occupational grading system. Furthermore, this level of seniority would have an impact on the legitimacy they could claim vis-à-vis the company's field managers. These concerns pointed towards a simpler system with a cut say, at the "three types" level (Fig. 2) comprising "rest areas", "essentials" and "Pop and Mum" fuel stations.

From a strategic perspective, and given BEST's ambitions as far as European market share was concerned, a finer classificatory system was required. A cut at just three types would suggest implementing CONCEPT among the "daily trips" kind of stores, and this would not be appropriate. The operational consequences of these debates were obviously major.

"If we just consider the assortment issues, a "7 types cut" means seven assortment structures with a very fine way to address consumer needs but a tremendous amount of work. Similarly, a "2 types cut" means two assortment structures with much more standardization for the consumers but a very simplified process and a lighter workload. These considerations cannot be answered without considering the number of category managers, the type of information systems, etc. and of course, it has an impact on the organization of the networks, the organization of the field managers etc. All this is complex. If you touch one subject, it impacts on so many others." (Mike, Marketing Director, Rapland typology meeting, Dec. 2003)

In addition, through the process of defining a typology, it slowly became clear that discussions oscillated between descriptions of existing networks with assignments of existing stores to categories, and a creative process whereby new concepts could be considered.

"In fact, we could operate our sites as BEST, the fuel distribution specialist, with a partner in the restaurant area, as well as a partner in the grocery business. Why not add a car wash specialist? In this configuration, I don't see what the job of a category manager will be! We'd better go and get a job at TESCO!" (Geoff, category manager, Rockland typology meeting, Oct. 2003) 


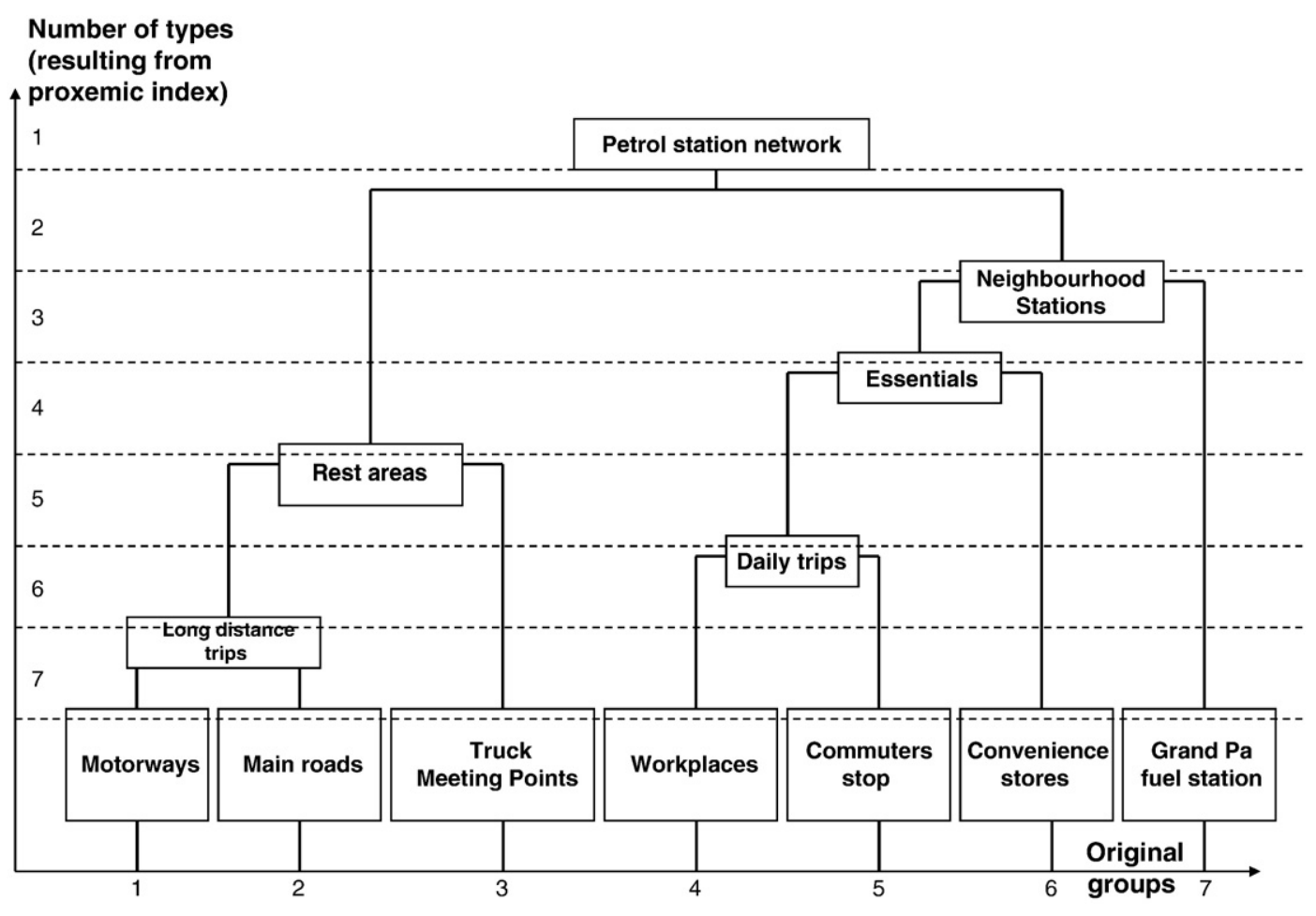

Fig. 1. Building a segmentation tree.

The mission to classify stores in order to decide where CONCEPT should be rolled out first became ever more complex. Mike was repeatedly exposed to the need for clarifying what CONCEPT stood for and define the functions of a petrol station. The more BEST succeeded in developing a retailer culture, as the company hoped for with the implementation of category management, the more it was getting closer to a pure retailer in terms of methods and processes and the more managers spotted a gap in expertise between pure retailers and
BEST. Two typical reactions from category managers followed: a) why shouldn't BEST get into a partnership with a "real retailer" since they had the know-how?, a "delegation" reaction; and: b) why should we be category managers at BEST rather than say, TESCO?, an "employability" reaction.

Mike recalled meetings where category managers complained because they could not deploy their methods to the fullest since their role was unclear but the issues run deeper. Should BEST operate the

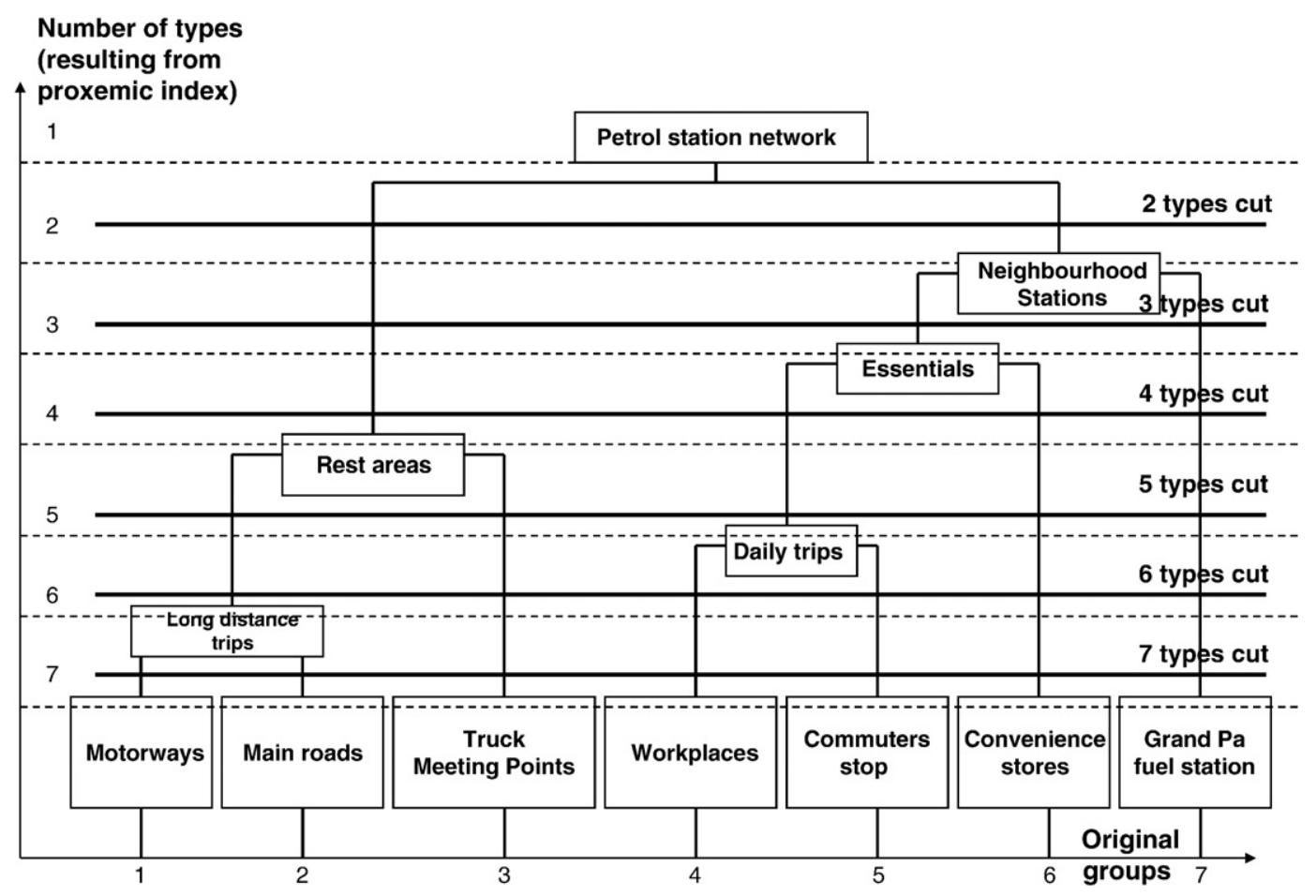

Fig. 2. Cutting the segmentation tree. 
activities themselves, what were they after with the implementation of CONCEPT, what was a petrol station for in the end?

\section{Analysis}

Our empirical case illustrates how the representation of the apparently mundane petrol station is the outcome of a long and often tortuous process of naturalization. As stressed by Bowker and Star (2000), classification systems are central to the management of a wide range of enterprises. In our case, the petrol station, as an object of management, had been kept stable for decades. A petrol station was traditionally regarded as a site for delivering fuel but it could also deliver many other things some of which are possibly more important than fuel, as far as profit margins and customer expectations are concerned.

The roll out of CONCEPT through the European network proved a bigger challenge than expected for BEST's managers. As far as superficial appearances are concerned, petrol stations look all the same. But the attempt to roll out CONCEPT sparked off a round of classification work showing that hardly any two stores were alike. To roll out a novel concept meant that the material weight of existing store formats had to be addressed.

The request of senior management that the network should be described in detail shows that classifications are both conceptual, in the sense of organizing activities and resources, and material in the sense of being inscribed in physical infrastructures. The deployment of CONCEPT raised questions about how to plan for its implementation within an existing infrastructure, but also raised issues related to standardization and productivity, the grading of category managers within the company's job classification system and finally, strategic decisions related to maintaining or selling off particular types of stores. In short, a categorization process that started as a technical exercise turned into a political debate about the current and future shape of the company's network.

The way the typology of petrol stations was developed shows an interesting facet of this political debate. Because Mike was a marketing director, he strived to put the consumer at the core of the research. The focus group process conducted by an external market research agency led to the generation of a number of abstract petrol station types. Mike's initiative demonstrated the role of a particular vision of marketing work and what counts as a legitimate method to connect firms to markets. Marketers represent the consumer voice inside the company and this voice should be firmly placed at the hub of decision-making. Orthodox marketing management and its prescriptions to segment markets and target offerings, framed the way Mike decided to approach CONCEPT's roll-out.

However, Mike felt that unless he could link consumer insights with representations category managers would recognize, his method would gain little currency within the company. Consumers could not be the sole driver of the classification process. Mike needed to enroll a range of other allies to arrive at a consensual agreement. Consumer insights needed to connect with the practices in use at the various marketing departments in BEST's country-based subsidiaries. The logic of productivity, embodied in the standardization and routinization of category management tasks, had to be confronted with the logic of market segmentation in order to cut down to size the burgeoning tree produced by consumer voices.

While enrolling allies, Mike was confronted with a number of alternative classification logics. Some managers wanted to maximize standardization, leading to a high level of homogeneity in the network, to enable junior category managers to do a job commensurate with their status. This was one way of making the retail network efficient. Classification could thus become a central instrument in the standardization of store management, which would mean standardizing relationship between diverse elements such as information systems, work patterns and the rest of the organization.

This logic of productivity was opposed by a different valuation of the network based on aspirations for market leadership and differentiation. Another set of managers proposed to create market niches so that the company would be able to touch a broad variety of consumer expectations as revealed by the focus group sessions. This initiative enhanced the role of category managers within the company and making them managers of narrower product categories. The clear differentiation of product families gave an opportunity for category managers to become experts and interlocutors of specialist suppliers, instead of managing a large group of products and shop configurations. This gave category managers a stronger sense of identity whilst opening up new opportunities for the study of "consumer needs" and giving a higher profile to managers with a general retail background. This shift in orientation, the new tasks combined with a higher level of complexity in the network, were the ingredients that forged a new identity for category managers.

And, while moving towards this new structure, new equivalencies were created as illustrated in the debate about employability and partnership, when comparing the retail capabilities of BEST vis-à-vis pure retailers. The further BEST moved in the direction of becoming a generic retailer, the more a job equivalence system developed in relation to pure retailers. Category managers at BEST would quickly become substitutable by other category managers with a retail background.

Finally, the number of clusters defined by BEST had a clear impact on markets. The proposed concepts of proximity shops, truck stops, workplaces or motorway rest stations performed different versions of the consumer-on-the-go. For example, the availability of stations on motorways involves designing offers for motorists who travel long distances. The snacking or coffee markets, for example, would be affected by the impact this would have on managers in charge of developing marketing plans for these stores. Similarly, the sandwich and restaurant markets would be impacted by the decision of setting up workplace stations in line with the focus groups' suggestions. By defining the needs of consumers in line with the types of stores generated by the new classification system, BEST performed multiple and differentiated versions of the "on-the-go consumer".

\section{Conclusions}

In this paper we explored how a naturalized and mundane entity, the petrol station, was re-defined by the apparently trivial decision of rolling-out a new store concept across a European network. This naturalized entity turned out to be a more complex object through its attachments to multiple worlds and its ability to present different facets to a variety of audiences (Kjellberg \& Helgesson, 2006). Its stability as an entity was entangled in a web of associations between markets (who are our customers and what they do they need from us?), managerial methods (e.g. category management), performance metrics (e.g. total margin) and physical infrastructures (e.g. store area and layout).

To develop a store typology turned out to be not just a matter of assembling technical descriptions of stores and equipment. As we have shown, a store typology had consequences for category management practices and the role of category managers is redefined, raising questions about their identity and legitimacy within the company and across the broader retail industry. It opened up a discussion space for implementing multiple versions of a petrol station aligned with multiple scenarios of what consumers "on-the-go" require.

Focus group sessions produced a typology stations based on consumer views that had to be aggregated and translated by moderators as well as filtered through the cluster analysis techniques of the market research agency. These categories were then confronted with the logic employed by category managers to translate consumers' characterizations into detailed descriptions of stores. Further translations were still required. Managerial processes had to be in place to implement particular store types and appropriately qualified managers had to be in charge for this to happen. This, in turn, raised issues about the company's capabilities to manage a diverse network, 
the possibility of partnering with specialist retailers and the strategic trade-offs involved in implementing a coarser or finer-grained classification system. In short, classification devices were used not just to organize a single domain (how many petrol stations types do we need and what should each type look like?) but to frame the relationship between multiple domains involved in stabilizing the petrol station as an object that can be classified, described and managed (Czarniawska \& Mouritsen, 2009).

Classification work requires extensive and protracted negotiations over what constitutes appropriate or relevant categories and how categories relate to other categories. Practices based on classificatory devices can be made to appear natural when the work of classification becomes invisible and taken for granted. The work of reclassification, as we have shown, is to disturb this complex set of links and to open up wider ranging discussions on what fits where and what equivalencies are articulated with other classification systems. As Bowker and Star (2000: 9) aptly put it: "There is a lot of hard labor in effortless ease".

\section{References}

Ackroyd, S., \& Hughes, J. (1992). Data collection in context. London: Longman.

Araujo, L. (2007). Markets, market-making and marketing. Marketing Theory, 7(3), $211-226$.

Azimont, F., \& Araujo, L. (2007). Category reviews as market-shaping events. Industrial Marketing Management, 36(7), 849-860.

Bowker, G. C., \& Star, S. L. (2000). Sorting things out. Classification and its consequences. Cambridge, MA: The MIT Press.

Callon, M. (1998). Introduction: The embeddedness of economic markets in economics. In M. Callon (Ed.), The laws of the market (pp. 1-57). Oxford: Blackwell.

Callon, M. (1999). Actor-network theory - The market test. In J. Law \& J. Hassard (Eds.), Actor network theory and after (pp. 181-195). Oxford: Blackwell.

Callon, M., Méadel, C., \& Raberahisoa, V. (2002). The economy of qualities. Economy and Society, 31(2), 194-217.

Callon, M., \& Muniesa, F. (2005). Economic markets as calculative collective devices. Organization Studies, 26(8), 1229-1250.

Carruthers, B. G., \& Espeland, W. N. (1991). Accounting for rationality: Double-entry bookkeeping and the rhetoric of economic rationality. American Journal of Sociology, 97(1), 31-69.

Cochoy, F. (2002). Une Sociologie du Packaging ou l'Ane de Buridan face au Marché. Paris: Presses Universitaires de France.

Cochoy, F. (2008). Calculation, qualculation, calqulation: Shopping cart arithmetic, equipped cognition and the clustered consumer. Marketing Theory, 8(1), 15-44.
Cooper, R. (1992). Formal organization as representation: Remote control, displacement and abbreviation. In M. Reed \& M. Hughes (Eds.), Rethinking organization: New directions in organization theory and analysis (pp. 254-272). London: Sage.

Czarniawska, B., \& Mouritsen, J. (2009). What is the object of management? In C. S. Chapman, D. J. Cooper, \& P. Miller (Eds.), Accounting, organizations, and institutions: Essays in honour of Anthony Hopwood (pp. 157-174). Oxford: Oxford University Press.

Desrosières, A. (2003). Du travail à la consommation: l'évolution des usages des enquêtes sur le budget des familles. Journal de la Société Française de Statistique, 144 (1-2), 75-110.

Espeland, W. N., \& Stevens, M. L. (1998). Commensuration as a social process. Annual Review of Sociology, 24, 313-343.

Gersick, C. (1989). Marking time: Predictable transitions in work teams. Academy of Management Journal, 32(2), 274-309.

Håkansson, H., \& Lind, J. (2004). Accounting and network coordination. Accounting Organizations \& Society, 29(1), 51-72.

Kjellberg, H., \& Helgesson, C. -F. (2006). Multiple versions of markets: Multiplicity and performativity in market practice. Industrial Marketing Management, 35(7), 839-855.

Kunda, G. (1992). Engineering culture: Control and commitment in a high-tech corporation. Philadelphia: Temple University Press.

Latour, B. (2005). Reassembling the social. An introduction to actor-network theory. Oxford: Oxford University Press.

Lezaun, J. (2007). A market of opinions: The political epistemology of focus groups. The Sociological Review, 55(s2), 130-151.

Mattsson, L. G. (2003). Understanding market dynamics. Potential Contributions to market(ing) studies from actor-network theory, Paper presented at the 19th IMP conference, University of Lugano, September.

Miller, P. (2001). Governing by numbers: Why calculative practices matter. Social Research, 68(2), 379-396.

Miller, P. (2008). Calculating economic life. Journal of Cultural Economy, 1(1), 51-64.

Miller, P., \& O'Leary, T. (1994). Governing the calculable person. In A. Hopwood \& P. Miller (Eds.), Accounting as social and institutional practice (pp. 98-115). Cambridge: Cambridge University Press.

Mouritsen, J., \& Thrane, S. (2006). Accounting, network complementarities and the development of inter-organisational relations. Accounting, Organizations \& Society, 31(3), 241-275.

Power, M. (2004). Counting, control and calculation: Reflections on measuring and management. Human Relations, 57(6), 765-783.

Porter, T. M. (2008). Locating the domain of calculation. Journal of Cultural Economy $1(1), 39-50$.

Sjögren, E., \& Helgesson, C. -F. (2007). The q(u)alifying hand: Health economics and medicine in the shaping of Swedish markets for subsidized pharmaceuticals. The Sociological Review, 55(s2), 215-240.

Smith, W. R. (1956). Product differentiation and market segmentation as alternative marketing strategies. Journal of Marketing, 21(1), 3-8.

Stark, D. (2009). The sense of dissonance: Accounts of worth in economic life. Princeton, NJ: Princeton University Press.

Watson, T. J. (1994). Search of management. Culture, control and chaos in managerial work. London: International Thomson Business Press. 